environmental effects as a cause of father-son phenotypic similarity by rearing young in groups (Table 1).

A slightly smaller mean body size of wild satellites has been interpreted as suggesting that poorly growing chicks disproportionately develop into satellites ${ }^{10}$. Small body size differences between morphs developed among our captives, despite ad libitum. food availability and benign environmental conditions (Table 3). However, growth parameters do not indicate that satellites grew more poorly than residents (Table 3 ). Rather than reflecting conditional development, the small difference in mean body size may be a correlated adaptation to the demands of each reproductive strategy. Independent males fight to establish courts and remain on them throughout the day ${ }^{18}$, both of which may favour larger size through increased social dominance and energy storage capacity. In contrast, satellites do not fight for courts, are freer to forage throughout the day, and spend more time flying, reducing the need for, and raising the physiological cost of, maintaining larger body size.

Theoretical and empirical investigations of behavioural development, social behaviour and life history of ruffs are henceforth justified in using a genetic equilibrium model for generating predictions against which to test field observations ${ }^{15,20-22}$. Our findings highlight the question of what selective conditions favour genetic polymorphism controlling morph development in this species $^{14}$, rather than quantitative inheritance ${ }^{23}$ or nearly complete environmental control ${ }^{24,25}$, as occurs in nearly all other species with alternative male mating tactics ${ }^{1-3,9.12} 13$

Received 5 June; accepted 16 August 1995

1. Dunbar, R. I. M. in Perspectives in Ethology Vol. 5 (eds Bateson, P. P. G. \& Klopfer, P. H. 385-431 (Plenum, New York, 1982)
2. Alcock, J. in Sexual Selection and Reproductive Competition in Insects (eds Blum, M. S. \& Blum, N. A.) 381-402 (Academic. New York, 1979).

Arak, A in Producers and Scroungers (ed. Barnard, C. J) 154-194 (Croom Helm, London, 1984)

Zimmerer. E. J. \& Kallman, K. D. Evolution 43, 1298-1307 (1989)

5. Ryan, M. J., Pease, C. M. \& Morris, M. R. Am. Nat. 139, 21-31 (1992).

6. Erbelding-Denk, C. et al. Behav. Genet. 24, 95-101 (1994).

Hogan-Warburg, A. J. Ardea 54, 109-229 (1966).

van Rhijn, J G Behaviour 47, 153-229 (1973).

. Caro T. M \& Bateson, P. Anim. Behav. 34, 1483-1499 (1986)

Höglund, J. \& Lundberg, A. Auk 106, 336-338 (1989).

11. van Rhijn, J. G. The Ruff (Poyser, London, 1991).

2. Dawkins, R. in Sociobiology: Beyond Nature/Nuture? (eds Barlow, G. W. \& Silverberg, J.) 331-367 (Westview, Boulder, CO, 1980).

13. West-Eberhardt, M. J. A. Rev. Ecol. Syst. 20, 249-278 (1989)

14. Lively, C. M. Am. Nat. 128, 561-572 (1986).

15. van Rhiin J. G Ibis 125, 482-498 (1983).

16. van Rhijn, J.

17. Hill

19. Sociobiol. 29, 137-145 (1987)

18. Lank, D. B. \& Smith, C. M. Behavl Ecol. Sociobiol. 29, 137-145 (1987).

19. Höglund, J.. Montgomerie, R. \& Widemo, F. Beh.

21. Austad, S. N. Am. Zool. 24, 309-320 (1984)

22. Maynard Smith, J. Evolution and the Theory of Games (Cambridge Univ. Press, 1982

23. Cade, W Science 212, 563-564 (1981).

24. Came, W. Proc. R. Soc. Lond. B256, 131-136 (1994).

25. Moran, N. A. Am. Nat. 139, 971-989 (1992).

26. Ricklefs, R. E. in Avian Biology Vol, 7 (eds Farner, D. S., King, J. R. \& Parkes, K. C.) 1-83 Ricklefs, R. E. in Avian Biology
(Academic, New York, 1983)

Hanotte, O., Burke, T. Armour, J. A. L. \& Jeffreys, A. J. Genomics 9, 587-597 (1991)

28. Bruford, M. W., Hanotte, O., Brookfield, J. F. Y. \& Burke, T. in Molecular Genetic Analysis of Populations: A Practical Approach (ed. Hoelzel, A. R.) 225-269 (IRL, Oxford, 1992).

Dixon, A. Ross, D. O'Malley S. C. L. \& Burke, T Nature 371, 698-700 (1994).

30. Wong Z. Wilson, V. Patel I. Povey S. \& Jeffreys, A. J. Ann hum Genet. 51, 269-288.

ACKNOWLEDGEMENTS, We thank A and R. Ohtonen, E. Pulliainen, other colleagues at the ACKNOWLEDGEMENTS. We thank A. and R. Ohtonen, E. Pulliainen, other colleagues at the University of Oulu, and Finnair's Technical Services Department for assistance in obtaining our data, and the landowners of Liminganlahti for permission to work with birds nesting along its shores. A. Krupa provided technical assistance with paternity analyses. The research was supported by grants from the US NSF, the H. F. Guggenheim Foundation, the National Geograph' Society, the United States Educational Foundation in Finland (Fulbright program), and Queen's
University at Kingston (to D.B.L.); the NSERC of Canada (to D.B.L. and F.C.); and the NERC, SERC and the Royal Society (to T.B.).

\section{Cell fate in the Arabidopsis root meristem determined by directional signalling}

\section{Claudia van den Berg*, Viola Willemsen*, Willem Hage ${ }^{\dagger}$, Peter Weisbeek* \& Ben Scheres*}

\author{
* Department of Molecular Cell Biology, Utrecht University, \\ Padualaan 8, $3584 \mathrm{CH}$ Utrecht, The Netherlands \\ + Netherlands Institute for Developmental Biology, Uppsalalaan 8, \\ 3584 CT Utrecht, The Netherlands
}

Postembryonic development in plants is achieved by apical meristems. Surgical studies and clonal analysis have revealed indirectly that cells in shoot meristems have no predictable destiny ${ }^{1-3}$ and that position is likely to play a role in the acquisition of cell identity $^{4-7}$. In contrast to animal systems ${ }^{8-10}$, there has been no direct evidence for inductive signalling in plants until now. Here we present evidence for such signalling using laser ablation of cells in the root meristem of Arabidopsis thaliana. Although these cells show rigid clonal relationships" ${ }^{11}$, we now demonstrate that it is positional control that is most important in the determination of cell fate. Positional signals can be perpetuated from more mature to initial cells to guide the pattern of meristem cell differentiation. This offers an alternative to the general opinion that meristems are the source of patterning information ${ }^{12}$.

The Arabidopsis thaliana root consists of single layers of epidermis, cortex, endodermis and pericycle, surrounding a vascular bundle ${ }^{13}$. The root meristem is derived from basal cells of the embryo proper that forms the initials for the different cell types present in the mature root, and from the hypophysis which generates the columella root cap and quiescent centre ${ }^{11}$ (Fig. 1). The consistency in cell fate and position suggests that cells are committed to form particular tissue types. This is supported by two $\beta$-glucuronidase promoter fusions specific for vascular and root cap cells, which are also expressed in the meristematic initial cells (Fig. $2 a, b$ ).

To determine whether root meristem cells behave according to their clonal origin or to their position, we applied laser ablation. Dead cells are compressed towards the periphery of the root (Fig. $3 a$ ), allowing neighbouring cells to invade their position. By recording the fate of the invading cell, the contribution of lineage or position can be investigated.

Upon ablation of all quiescent centre cells, the dead cells become flattened and are displaced towards the root tip. Cells of the proximal vascular bundle occupy the former position of the dead cells. These cells no longer express the vascular marker (Fig. 2c) but instead express the root cap marker (Fig. $2 d$ ). Hence the clonal boundary set by the first zygotic division, separating future vascular and root cap cells, does not restrict developmental potential. Furthermore, information guiding cell fate along the apical-basal axis in the root tip is permanently present. These results confirm earlier regeneration studies ${ }^{14-17}$ but also show that global redifferentiation is not necessary for cell-fate switching.

We investigated whether positional information can determine cell fate in the radial plane. Cortical initials divide asymmetrically to produce cortex/endodermis cells (Fig. 3a). Upon ablation of these initials, pericycle cells invade and divide periclinally. This maintains the pericycle cell file and generates new cells in the cortical cell file (Figs $3 a, 4 b$ ). Pericycle cells are smaller than cortical cells, so more than one pericycle cell invades, thus enlarging the typical number of eight cortical cells. The former pericycle cells subsequently divide asymmetrically (Figs 3b, 4b), generating cortical and endodermal cell files. Suberin staining revealed a casparian strip in all prospective endodermal cells, illustrating their differentiation to endodermal fate (Fig. 3c). Therefore, pericycle cells switch fate when moved over radial clonal boundaries. 

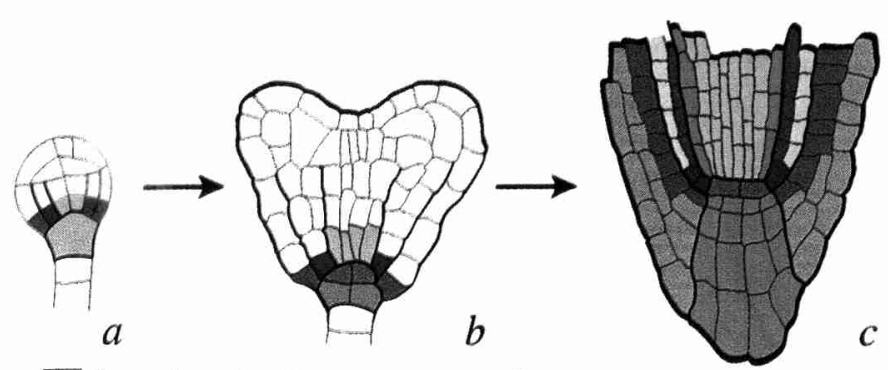

hypophyseal cell

vascular bundle and pericycle

cortex initial

cortex and endodermis

epidermis

lateral root cap

columella

quiescent centre
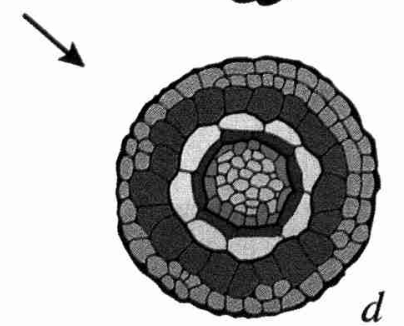

FIG. 1 Schematic representation of the Arabidopsis root meristem $\operatorname{origin}^{11,13}$. a, Early globular embryo; $b$, early heart-stage embryo; $c$, seedling root (longitudinal); $d$, seedling root (transverse). The root meristem is derived from the basal cells of the embryo proper and from the hypophysis (a). The initial cells for the different tissue types are separated early during embryogenesis. The cortical initial cells first divide anticlinally, generating cortical daughters, whereupon these divide periclinally to give rise to cortex and endodermis. Epidermal initials form epidermis and lateral root cap. The hypophysis gives rise to the columella and the quiescent centre. The four quiescent centre cells cease dividing after formation ${ }^{13}$.
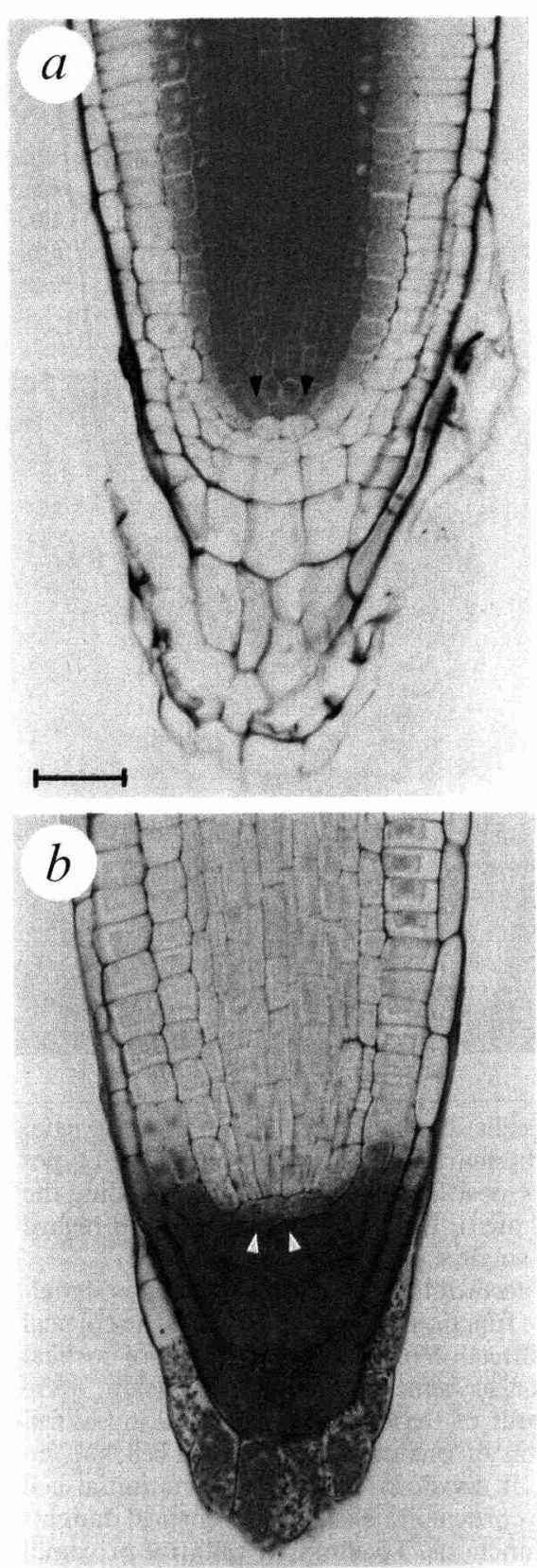
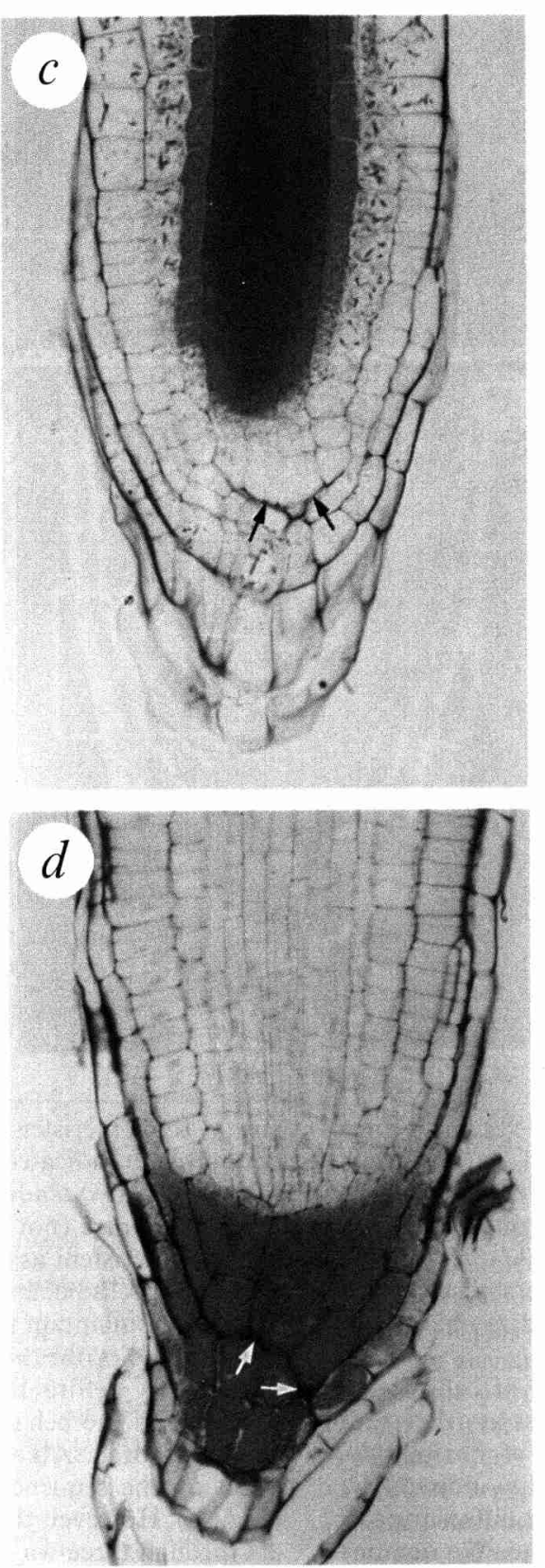

FIG. 2 Allocation of fate is determined by cell position rather than by clonal origin. $\beta$-Glucuronidase reporter gene expression in $a$, root vascular tissue, and $b$, root cap. Note the expression in initial cells (arrowheads). $c, d$, Expression of reporter genes 5 days after ablation of the quiescent centre. Dead cells are displaced towards the root tip (arrows; $n>50$ ). Cells at the former position of the quiescent centre form continuous files with the vascular bundle $(n>50)$. These cells always cease to express the vascular marker $(c)(n=8)$. In contrast, they now express the root-cap marker $(d)$ $(n=13)$. Thus cells that cross the clonal boundary switch fate according to positional cues. Scale bar, $25 \mu \mathrm{m}$.

METHODS. Two-day-old seedlings were incubated with $10 \mu \mathrm{g} \mathrm{ml}^{-1}$ propidium iodide (Sigma) and examined using a confocal laserscan microscope $(25 \mathrm{~mW}$ argon-ion laser, mrc-600, Bio-Rad, Zeiss Axiovert). Propidium iodide surrounds living cells, thereby outlining individual cells (compare with Fig. $3 e$ ) and presensitizes the cells for ablations (not shown). Individual cells were ablated by focusing the unfiltered laser beam for $1 \mathrm{~s}$ on a specific position and plane of focus. Successfully ablated cells were stained by the entry of propidium iodine. The ablated cells could be restained following growth. Remnants of ablated cells retained a fluorescent signal after fixation and embedding (not shown). Successfully ablated roots, grown for various periods, were stained in $0.5 \mathrm{mg}$ $\mathrm{ml}^{-1} \mathrm{X}$-gluc (Biosynth AG) for $2 \mathrm{~h}$, fixed overnight in $70 \%$ ethanol. Dehydration, embedding and sectioning were performed as described ${ }^{11}$ The vascular-marker line (553-643) contains an enhancer trap construct ${ }^{26}$. The root-cap marker line contains the 35S CAMV promoter B2 subdomain fused to the $\beta$-glucuronidase gene $^{27}$. 
$a$

FIG. 3 Positional information is generated from cells within the same tissue type and is perpetuated distally. a, Ablation of one cortical initial cell. The dead cell is pressed peripherally (arrowhead) and two pericycle cells are occupying its former position $(n=35)$. These have divided periclinally to generate cells in both the cortical and pericycle layer (open arrows). Note the asymmetric division in untreated cortical initials (arrow). b. Three days after ablation of a cortical initial. The invading pericycle cells have generated a larger cortical (c) and a smaller endodermal cell (e) $(n=15)$. Two pericycle cells occupy the position of one dead cortical cell, forming 9 cortical and endodermal cells. $c$, Fresh section of a root at a similar stage as that in $b$. Suberin staining shows the endodermis-specific casparian strip in all nine endodermal cells $(n=7)$. d, Section of a root, one day after an epidermal initial cell ablation. The dead cell is compressed peripherally (arrowhead). The invading cortical initial has divided to form new cells in the epidermal layer (arrows; $n=21$ ). These cells later generate new root cap cells ( $n=8$; not shown). e. Confocal laser scan of a root 4 days after ablation of 3 cortical initial daughters. The cell file (vertical bar) of at least $3(n=13)$ or even $4(n=6)$ cells under the dead fluorescent cell (arrow) arises from one initial which has divided anticlinally and not periclinally. $f$, Scan of a root 4 days after ablation of one epidermal, one cortical and one pericycle daughter. The dead cells are compressed (arrow) and the underlying initial has undergone normal anti- and periclinal divisions $(n=11)$. Scale bars, $25 \mu \mathrm{m}$.

METHODS. Sections were stained with $0.1 \%$ Astra blue (Merck) and suberin-stained as described ${ }^{11.25}$. For ablation of 3 cortical daughters, a c-apochromat $40 * / 1.2 \mathrm{~W}$ corr. lens (Zeiss) was used to score successful ablations by making an X-Z-scan. If the dead cells were rapidly compressed to the root periphery, proximal signalling was restored, before the cortical initial could perform a number of divisions ( $n=$ 17). If the dead cells stayed in place, always 3 or 4 cells without asymmetric division were seen under the compressed dead cell $(n=19)$.

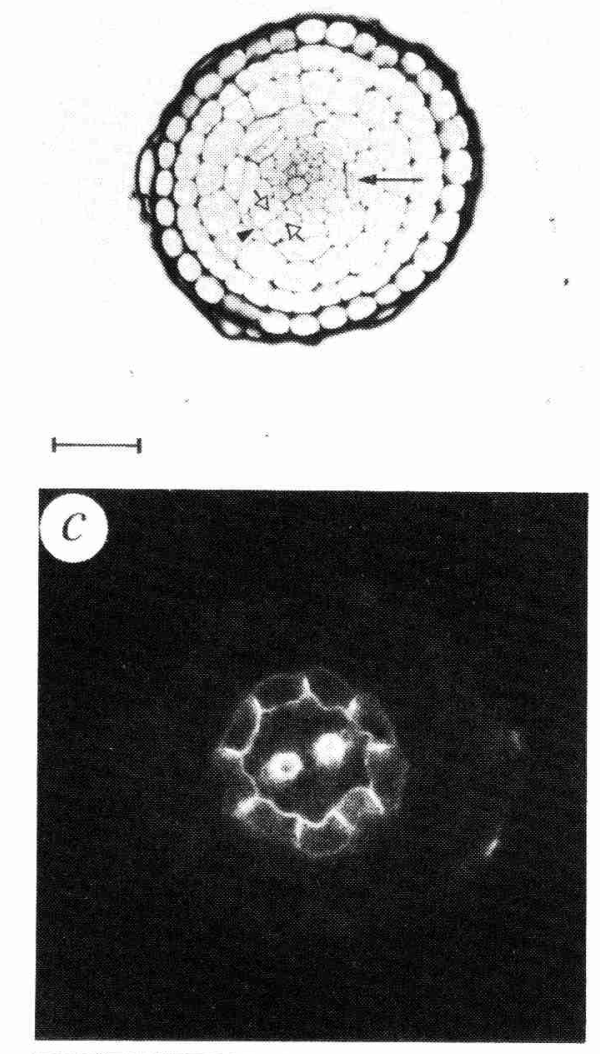

b

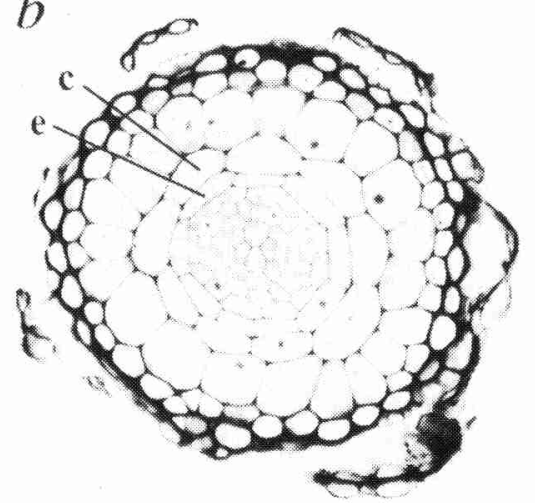

$d$
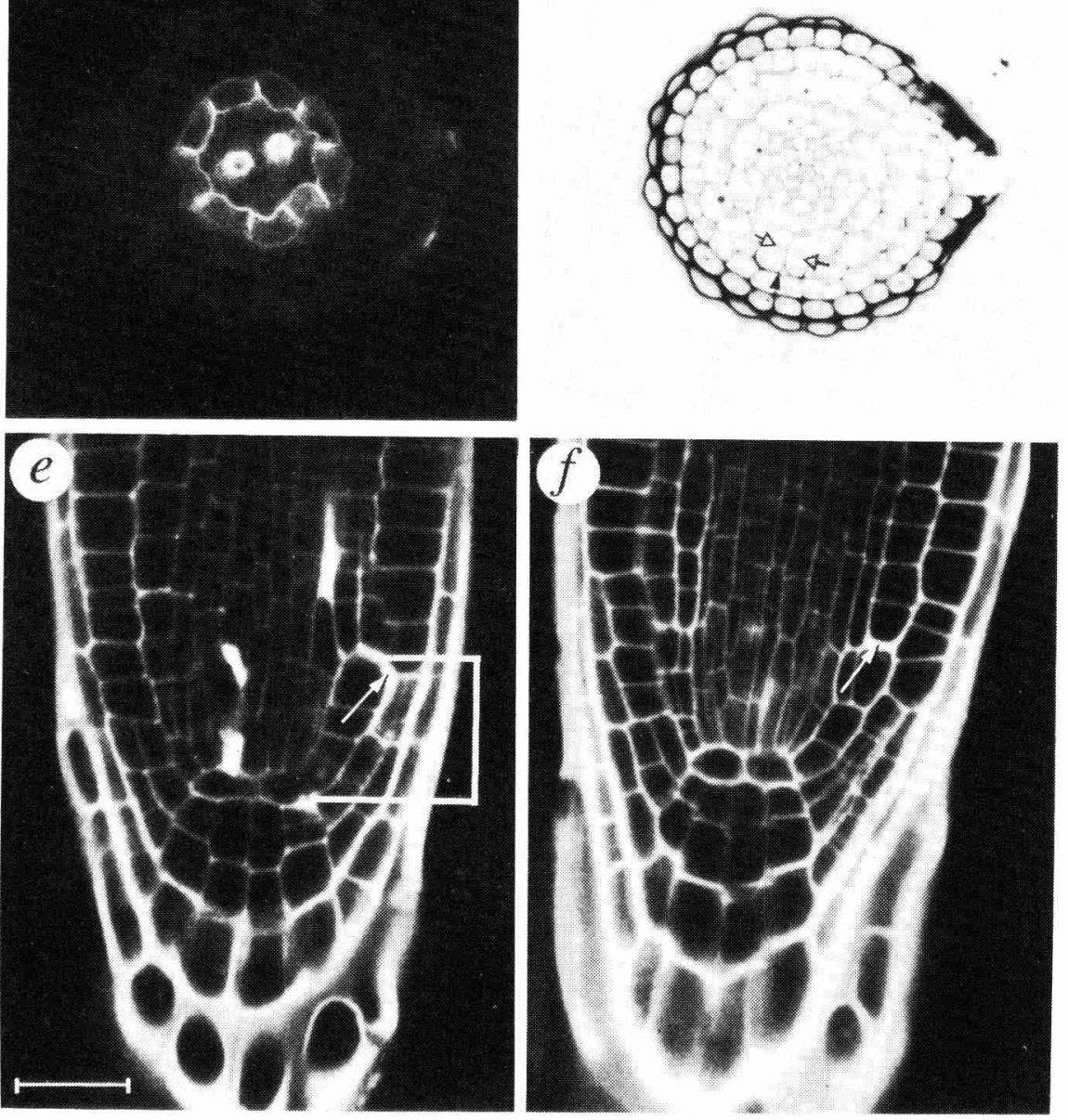

Epidermal initials generate the epidermal cell file but also form the lateral root cap (Fig. 1). After ablation of an epidermis initial, a neighbouring cortical cell occupies its position. It divides and generates a daughter in the epidermal layer that performs a characteristic periclinal division (Fig. $3 d$ ). Upon prolonged growth, intact root cap and epidermis layers arise. Therefore, besides pericycle, cortical cells also respond to changes in position.

Surgical experiments have revealed flexibility of cell fate in both root and shoot apices, but did not demonstrate the exact mode of regeneration and the cellular origin of flexibility ${ }^{16}$. Clonal analysis has demonstrated cell flexibility indirectly ${ }^{18}$. Here, we show directly that a shift of cells into a different position is the only causal necessity for changing fate. We demon- strate that meristem cells change fate, despite the partial commitment indicated by marker-gene expression. All cell types that we tested can adopt position-dependent fates, including the quiescent centre (not shown). It is therefore tempting to regard the root meristem as a single equivalence group ${ }^{19,20}$.

If initial cells behave according to position, continuous signalling should maintain the functional pattern. We used the cortical initial cell to probe the direction of signals. Daughters of cortical initial cells before their asymmetric periclinal division, were ablated and the behaviour of the underlying cortical initial cell was monitored. Ablation of one cortical daughter cell had no effect on the sequence of divisions occurring in the initial cell (Fig. 4c). However, this cortical initial still abuts cortical daughters through three-way junctions. To eliminate putative proximal 
FIG. 4 Schematic representations of cortical initial and derivative cell ablation experiments. Ablated cells are depicted in red; the colours of the cells are as in Fig. 1. a, Position of cortical initial cell and derivatives in one of eight identical meristem cell files. The cortical initial divides transversally, generating a cortical daughter cell which subsequently divided periclinally to form an endodermal and cortical cell file $(97 \% ; n=215)$. $b$. Ablation of a cortical initial. The dead cell is compressed to the outside and its position is filled with pericycle cells. These switch fate and behave as cortical initials. $c$, Ablation of one cortical initial daughter cell. The underlying cortical initials perform normal periclinal and anticlinal cell divisions $(n=16)$. Note that the cortical initial is not isolated from all cortex daughter cells and passage of signals from the daughters of neighbouring initials to the middle initial can still occur. $d$, The isolation of one cortical initial upon ablation of 3 cortical daughter cells. The cortical initial is still able to perform proliferative divisions to generate daughter cells, but asymmetric divisions are absent. e, Control experiment in which one epidermal, one cortica daughter and one pericycle cell above one cortical initial are ablated. A similar number of dead cell remnants contacting one initial cell are present (as in $d$ ), but the initial is not isolated from all the cortica daughters. The underlying initial performs its normal division pattern.

signals in the cortical cell file, we ablated three cortical daughter cells and scored the effects on the underlying, now isolated, initial cell. This initial cell could still generate a daughter cell but was unable to divide asymmetrically to generate the cortex and endodermis files, generating a single file of cells instead (Figs $3 e, 4 d$ ). To eliminate the possibility that this is a wounding effect, we ablated three neighbouring cells, but this time one cortical, epidermal and pericycle daughter cell. In this case, one cortical initial cell abutted three dead cells but was not isolated from other cortical cells. Here, the cortical initial cell performed its norma anti- and periclinal divisions (Figs $3 f, 4 e$ ). We conclude that information guiding allocation of cell fate in the radial plane is propagated through an individual cell layer and is directed towards the tip (Fig. $4 f$ ). Thus in the root meristem, inductive processes appear to specify initial cells, whereby the mature daughter cells act as a patterning template. Similarly, in Xenopus laevis when single cells are transplanted to heterotopic sites, they differentiate to conform with their neighbouring host cells ${ }^{21}$. Our results indicate that meristem initial cells are not generators of pattern, as is generally assumed ${ }^{12}$, but rather perpetuate an existing pattern.

Arabdidopsis mutants that lack asymmetric cortical divisions offer a potential starting point for unravelling the molecular mechanisms of position-dependent inductive signalling in plants $^{22,23}$. Experiments on Fucus embryos have indicated that cell wall components are involved in cell fate decisions ${ }^{24}$. Alternatively, in the Arabidopsis root at least one cell layer is symplastically coupled and so cytoplasmic inductive signals might be restricted to cell layers ${ }^{25}$

\footnotetext{
Received 25 July; accepted 29 August 1995

1. Pilkington, M. New Phytol. 28, 37-53 (1929).

2. McDaniel, C. N. \& Poethig, R. S. Planta 175, 13-22 (1988).

. Jegla D. E Sussex I. Mevl Biol 131, 215-225 (1989).

4. Wardlaw, C. W. Phil. Trans. Soc. London B 234, 583-604 (1950).

Wardlaw, C. W. Phil. Trans. Soc. London B 234, 583-604 (1950).

6. Steeves, T. A. \& Sussex, I M. in Patterns of Plant Development 2nd edn 86-99 (Cambridge Univ. Press, New York, 1989)

. Dawe, R. K. \& Freeling, M. Plant J. 1, 3-8 (1991)

8. Spemann, H. \& Mangold, H. Roux's Arch. dev. Biol. 100, 599-638 (1924).

9. Greenwald, I. \& Rubin, G. M. Cell 68, 271-281 (1992).

9. Greenwald. \& Rubin, G. M. Cell 68, 271-281 (1992).

11. Scheres, B. et al. Development 120, 2475-2487 (1994).

11. Scheres, B. et al. Development 120, 2475-2487 (1994).
12. Alberts, B. et al. in Molecular Biology of the Cell 3rd edn 1108-1113 (Garland, New York, Alberts, B. et al. in Molecular Biology of the Cell 3 rd

13. Dolan,

14. Barlow, P. New Phy. 73, $937-954$ (1974).

15. Feldman, L. J. \& Torrey, J. G. Am. J. Bot. 63, 345-355 (1976).

16. Sussex, I. M. Cell 56, 225-229 (1989).
}

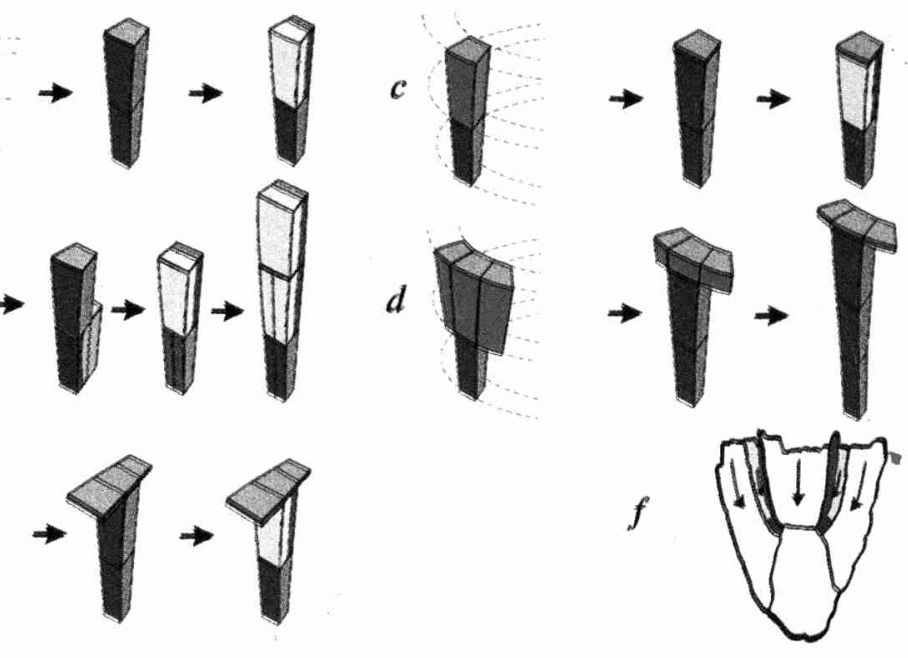

$f$, Model representing pattern perpetuation by positional signals in the root meristem. Colours represent cortical/endodermal cell layer for which we have demonstrated directional flow of positional cues (arrows). Other arrows indicate that signals can similarly be perpetuated within other individual cell layers.
17. Schiavone, F. M. \& Racusen, R. H. Development 113, 1305-1313 (1991).

18. Poethig, R. S. Am. J. Bot. 74, 581-594 (1987).

19. Sulston, J. E. \& White, J. G. Devl Biol. 78, 577-597 (1980)

20. Kimble, J. Devl Biol. 87, 286-300 (1981).

21. Haesman, J., Wylie, C. C., Hausen, P. \& Smith, J. C. Cell 37, 185-194 (1984)

22. Benfey, P. N. et al. Development 119, 57-70 (1993).

23. Scheres, B et al. Development 121, 53-62 (1995).

.

Duckett, C. M. Oparka, K. J. Prior, D. A. M. Dolan, L. \& Roberts, K. Development 120, 3247-3255 (1994)

26. Goddijn, O. J. M., Lindsey, K., van der Lee, F. M.. Klap, J. C. \& Sijmons, P. C. Plant J. 4, 863-873 (1993)

27. Benfey, P. N., Ren, L. \& Chua, N.H. EMBO J. 9, 1685-1696 (1990)

ACKNOWLEDGEMENTS. We thank P. Sijmons and MOGEN for the vascular-specific marker line 553-643: P. Benfey for the root-cap marker: F. Kindt, R. Leitho. W. Veenendaal and P. Brouwer for photography; D. Smit and F. Gerards for artwork; I. Sussex for his suggestions and H. Mckhann for critically reading the manuscript.

\section{Salt-resistant hypertension in mice lacking the guanylyl cyclase-A receptor for atrial natriuretic peptide}

\author{
M. James Lopez ${ }^{*} \dagger$, Stephen K.-F. Wong $\dagger$, \\ Ichiro Kishimoto $\nmid \ddagger$, Susan Dubois $\nmid \xi$, \\ Valerie Mach $\$$, Janet Friesen $\dagger$, \\ David L. Garbers $\dagger \ddagger$ \& Annie Beuve $\dagger \ddagger$
}

\footnotetext{
¥ The Howard Hughes Medical Institute and the Departments of † Pharmacology, ${ }^{*}$ Pediatrics and $\S$ Internal Medicine, University of Texas Southwestern Medical Center, Dallas, Texas 75235-9050, USA
}

AROund half of all humans with essential hypertension are resistant to salt (blood pressure does not change by more than $5 \mathrm{~mm}$ $\mathrm{Hg}$ when salt intake is high) ${ }^{1-5}$, and although various inbred strains of rats display salt-insensitive elevated blood pressure ${ }^{6}$, a gene defect to account for the phenotype has not been described. Atrial natriuretic peptide (ANP) is released from the heart in response to atrial stretch and is thought to mediate its natriuretic and vasorelaxant effects through the guanylyl cyclase-A receptor (GC-A) ${ }^{7}$. Here we report that disruption of the GC-A gene results in chronic elevations of blood pressure in mice on a normal salt diet. Unexpectedly, the blood pressure remains elevated and unchanged 